\title{
Assessment of proprioceptive exercises in the treatment of rotator cuff disorders in nursing professionals: a randomized controlled clinical trial
}

\author{
Avaliação dos exercícios proprioceptivos no tratamento dos distúrbios \\ do manguito rotador em profissionais de enfermagem: um estudo clínico \\ controlado e randomizado
}

Lisandra V. Martins, Maria H. P. Marziale

\begin{abstract}
Background: Shoulder pain in nursing professionals may lead to limitations in occupational and daily activities and consequently interfere with quality of life. Objective: To compare the effects of two physical therapy programs which differed in the proprioceptive exercises used on the nursing professionals with rotator cuff disorder, according to quality of life, work satisfaction indicators, and pain intensity. Method: This study was an experimental, randomized, prospective, comparative trial with quantitative data analysis. The data sampling was carried out between the months of June 2010 and July 2011 by means of a questionnaire containing socio-demographic and professional information, the Western Ontario Rotator Cuff Index (WORC), the Occupational Stress Indicator (OSI), and the Visual Numeric Scale (VNS). Based on randomization, subjects were divided into two groups. Group 1 (control) was submitted to stretching and strengthening exercises and cryotherapy. Group 2 (experimental) was treated with the same protocol as the control group, with the addition of proprioception exercises. The data was analyzed by means of the Statistical Package for the Social Science version 16.0 for Windows. Results: After physical therapy intervention, significant reduction in pain levels occurred in both groups, with a significant improvement in quality of life for Group 2. No changes were observed in the work satisfaction indicators after the two types of physical therapy interventions. Conclusions: The proprioceptive exercises were important in the treatment of musculoskeletal disorders, however the results did not allow us to determine which treatment was the most effective as there was no significant difference between groups. Trial registration ClinicalTrials.gov NCT01465932.
\end{abstract}

Keywords: nursing staff; shoulder; physical therapy; quality of life; job satisfaction.

\section{Resumo}

Contextualização: A dor no ombro em profissionais de enfermagem pode acarretar limitação das atividades diárias e ocupacionais e interferir na qualidade de vida. Objetivo: Comparar o efeito da aplicação de dois programas fisioterapêuticos diferenciados pelos exercícios de propriocepção em trabalhadores de enfermagem com desordem do manguito rotador, segundo indicadores de qualidade de vida, satisfação no trabalho e intensidade da dor. Método: Trata-se de um estudo experimental, randomizado, prospectivo, comparativo, com análise quantitativa dos dados. A coleta de dados foi realizada no período de junho de 2010 a julho de 2011, por meio de um questionário sociodemográfico e profissional, questionário Western Ontario Rotador Cuff Index (WORC), Escala de Satisfação no Trabalho (Occupational Stress Indicator) e Escala Visual Numérica (EVN) para intensidade da dor. Após randomização, os sujeitos foram alocados em dois grupos. No Grupo 1 (controle), foram aplicados exercícios de alongamento, fortalecimento e crioterapia. No Grupo 2 (experimental), foram realizados os mesmos exercícios que no Grupo 1 acrescidos de exercícios proprioceptivos. Os dados foram analisados por meio do Statistical Package for the Social Science, versão 16.0 para Windows. Resultados: Após os tratamentos fisioterapêuticos, houve melhora significativa da dor nos sujeitos dos dois grupos e da qualidade de vida nos trabalhadores do Grupo 2. Não houve alteração dos indicadores de satisfação no trabalho nos dois grupos. 
Conclusões: Os exercícios proprioceptivos foram importantes no tratamento dos distúrbios osteomusculares. No entanto, os resultados não permitiram inferir a melhor efetividade deles em relação ao outro tratamento, pois não houve diferença significativa entre os grupos. Ensaio clínico registrado no ClinicalTrials.gov NCT01465932.

Palavras-chave: equipe de enfermagem; ombro; fisioterapia; qualidade de vida; satisfação no trabalho.

\section{Introduction : :}

Healthcare professionals, including those related to the nursing field, carry out their activities in an environment that can expose them to various occupational risks, leading to physical and emotional problems and interfering in quality of life ${ }^{1}$. Occupational quality of life is a topic of interest in the current literature and has become an important tool for organizations. In general, it is associated with factors such as health, longevity, occupational satisfaction, pleasure, salary, and disposition, and it can define vital aspects of life, such as status and personal identity ${ }^{2}$.

Some studies indicate that nurses are at high risk of acquiring work-related musculoskeletal disorders as an increasing number of disabled workers can be seen due to compromised musculoskeletal function ${ }^{3-5}$. Some tasks, which require pulling or pushing hospital beds and stretchers with the arms at extension especially during patient transfers, are conducted with static postures and elevation maneuvers of the shoulders and have been associated with shoulder pain ${ }^{6}$.

The assessment of the influence of shoulder pain on quality of life is important in order to determine prognostics, guide treatment, and establish expected outcomes in treatment. It also permits evaluation of the level of disability from the patient's perspective and provides information regarding what is actually important to the patient, such as return to recreational and occupational activities ${ }^{7}$.

Therefore, this research is relevant to the fields of physical therapy and nursing and it is of fundamental importance to nursing professionals and healthcare administrators, given that shoulder disorders can compromise the performance of daily and occupational activities, alter levels of occupational satisfaction and quality of life, and also promote absenteeism. The objective was to compare the effects of a physical therapy program consisting of stretching exercises, strengthening, proprioception, and cryotherapy with another physical therapy program consisting of stretching exercises, strengthening, and cryotherapy in nurses suffering from rotator cuff disorders through the use of quality of life indicators, work satisfaction, and pain intensity.

\section{Method : :}

This study represents an exploratory, randomized, prospective, and comparative trial with quantitative data analysis. The study was conducted in the Rehabilitation Center (RC) of the Clinical Hospital of the Medical School of Ribeirão Preto of Universidade de São Paulo (USP), Ribeirão Preto, SP, Brazil. The study included the hospital's nursing professionals (registered nurses, nurse technicians, and nurse's aides) with a medical diagnosis of rotator cuff disorder, who received physical therapy care at the RC during the periods of June 2010 and July 2011.

The inclusion criteria of the sample were: employment as a registered nurse, nurse technician, or nurse's aide at the Institution; a medical diagnosis of rotator cuff disorder (impingement syndrome); availability and interest in participating in the study; signing an informed consent form. The exclusion criteria were: presence of significant pain that would prevent the performance of the physical therapy program; presence of medically diagnosed cognitive alterations; presence of associated disabling diseases, previous shoulder surgery, and other specific disorders of the shoulder complex (adhesive capulitis, degenerative alterations of the glenohumeral joint, tendinous calcification); absence from more than three physical therapy sessions (consecutive or not); use of medication or other treatment for shoulder pain (example: acupuncture, massage) during the physical therapy treatment; unwillingness to take part in the study.

No sample size calculations were conducted in this study since the number of subjects was dependent on the influx of patients sent to physical therapy care at the $\mathrm{RC}$ throughout the duration of the study. All subjects who fulfilled the inclusion criteria were invited to participate in the study.

All subjects were then randomized and allocated to Group 1 (control) or Group 2 (experimental) by a person not participating in the application of data collection instruments and/or rehabilitation programs. Group 1, the control group, was composed of subjects who were submitted to stretching and strengthening exercises, followed by cryotherapy to the shoulder. Group 2 was formed by subjects who received stretching and strengthening exercises, proprioceptive drills, and cryotherapy to the shoulder. 
The study was conducted in four different phases.

Phase 1 - Application of data collection instruments (before).

A previously trained physical therapist, who did not participate in the exercise program, conducted the application of four instruments:

The first was a questionnaire containing occupational and socio-demographic information, as well as information related to the pathophysiology of the shoulder (including measurement of shoulder range of motion with a goniometer). The second was the Western Ontario Rotator Cuff Index (WORC). This instrument was chosen since it represents a reliable tool for measuring quality of life in patients with rotator cuff disorders ${ }^{8}$. It is available in Portuguese and has been validated for the Brazilian culture9. The third questionnaire was the Occupational Stress Indicator (OSI). This scale has also been translated and validated ${ }^{10}$ and allows the assessment of occupational satisfaction according to 22 psychosocial aspects by means of 6-point Likert scales, which vary from enormous dissatisfaction to enormous satisfaction ${ }^{11}$. To evaluate the intensity of pain, we used the Visual Numeric Scale (VNS). This scale consists of a graded line ranging from zero to ten. The left end represents "no pain" and right end represents the "worst possible pain". The use of this scale is justified by its short application time and applicability in clinical and research contexts ${ }^{12}$.

Phase 2 - Distribution of subjects in Groups 1 and 2.

In order to promote greater homogeneity with the clinical status of the patients, subjects were initially subdivided according to the presence or absence of shoulder movement deficits (measurement of shoulder range of motion with a goniometer) and the level of pain intensity, as shown by the Visual Numeric Scale (VNS).

Pain levels less than or equal to three were considered mild. Pain levels greater than three and less than or equal to seven were considered moderate, and pain levels greater than seven, severe ${ }^{13}$. After pain classification, the subjects were divided into six subgroups: a) mild pain and no deficit; b) mild pain and deficit; c) moderate pain and no deficit; d) moderate pain and deficit; e) severe pain and no deficit; f) severe pain and deficit.

The randomization occurred so that the first subject of each subgroup was randomly assigned to one group and the second subject was assigned to the other group, and so on.

Phase 3 - Application of treatment programs.

In this phase, the specific treatment programs were applied to Group 1 and Group 2.

Group 1: Strengthening and stretching exercises were carried out for muscles of the shoulder complex, followed by ice application.
Group 2: The same exercises were applied, with the addition of proprioceptive exercises.

Both rehabilitation programs were composed of two sessions per week for six weeks, with a progressive increase in resistance during strengthening exercises at every three sessions, according to a protocol ${ }^{14}$ based on several studies ${ }^{15-19}$.

All exercises were selected in accordance with various studies that assessed shoulder rehabilitation in patients with rotator cuff disorders ${ }^{14-19}$. Both rehabilitation programs consisted of pendulum exercises of the shoulder, stretching of the cervical spine and shoulder muscles, exercises with a stick (to maintain or improve range of motion), exercises to strengthen the muscles of the rotator cuff and scapular stabilizers ${ }^{14-20}$.

Only in Group 2, proprioceptive exercises were conducted. These exercises included exercises with joint position, rhythmic stabilization and repositioning of the members, unstable base, proprioceptive neuromuscular facilitation, and speed and accuracy ${ }^{17,19}$.

Cryotherapy was used in both groups (through the ice pack) because it is a resource of great importance in clinical practice and widely used for reducing pain in shoulder impingement syndrome. The duration of application was 20 minutes, based on recommendations from the literature and performed at the end of the session to reduce the pain and/or inflammation ${ }^{16,19}$.

During treatment, subjects of both groups also received verbal orientation regarding appropriate joint protection and adequate body posture ${ }^{16,19,21}$. The instructions were to maintain upright posture while working; avoid carrying objects or pushing to stay with the affected upper limb; avoid repetitive motion of lifting the arms above the head level ${ }^{16,19,21}$.

Phase 4 - Application of data collection instruments (after).

The physical therapist responsible for the application of data collection instruments from phase 1 of the study reapplied the WORC, OSI, VNS, as well as a questionnaire for profile characterization of nursing professionals after the exercise programs. These questionnaires were applied one day after the intervention by the same physical therapist responsible for the implementation of the instruments in the first phase of data collection in order to compare the results of treatment programs. The therapist was blinded to group allocation.

This study was approved by the Clinical Research Ethics Committee of the Clinical Hospital of the Medical School of Ribeirão Preto of USP under protocol number HCRP 5549/2010. All subjects signed an informed consent form. This study is registered at ClinicalTrials.gov (http://www.clinicaltrials.gov) under identification number NCT01465932.

The statistical analysis was carried out in the Statistical Package for the Social Science (SPSS), version 16.0. Nonparametric tests were used for data analysis: paired samples were analyzed with the Wilcoxon test, while independent 
samples were processed with the Mann-Whitney test. Values of $\mathrm{p}<0.05$ were considered to be statistically significant.

\section{Results $:: \therefore$}

The sample was initially composed of 20 subjects. All subjects suffered from shoulder impingement syndrome, of which four were excluded due to the following factors: lack of commitment to the rehabilitation program (more than three absences, consecutively or not); dengue fever; and medication use (not only due to shoulder pain, but migraine, fibromyalgia and low back pain). Thus, the final sample was composed of 16 nursing professionals, with 8 subjects randomly allocated to each group. The flow diagram shows the enrollment, allocation, follow-up and analysis of subjects in Groups 1 and 2 (Figure 1).

In light of the results obtained in this study, it was possible to verify that most of the nursing professionals who sought physical therapy care due to shoulder impingement syndrome

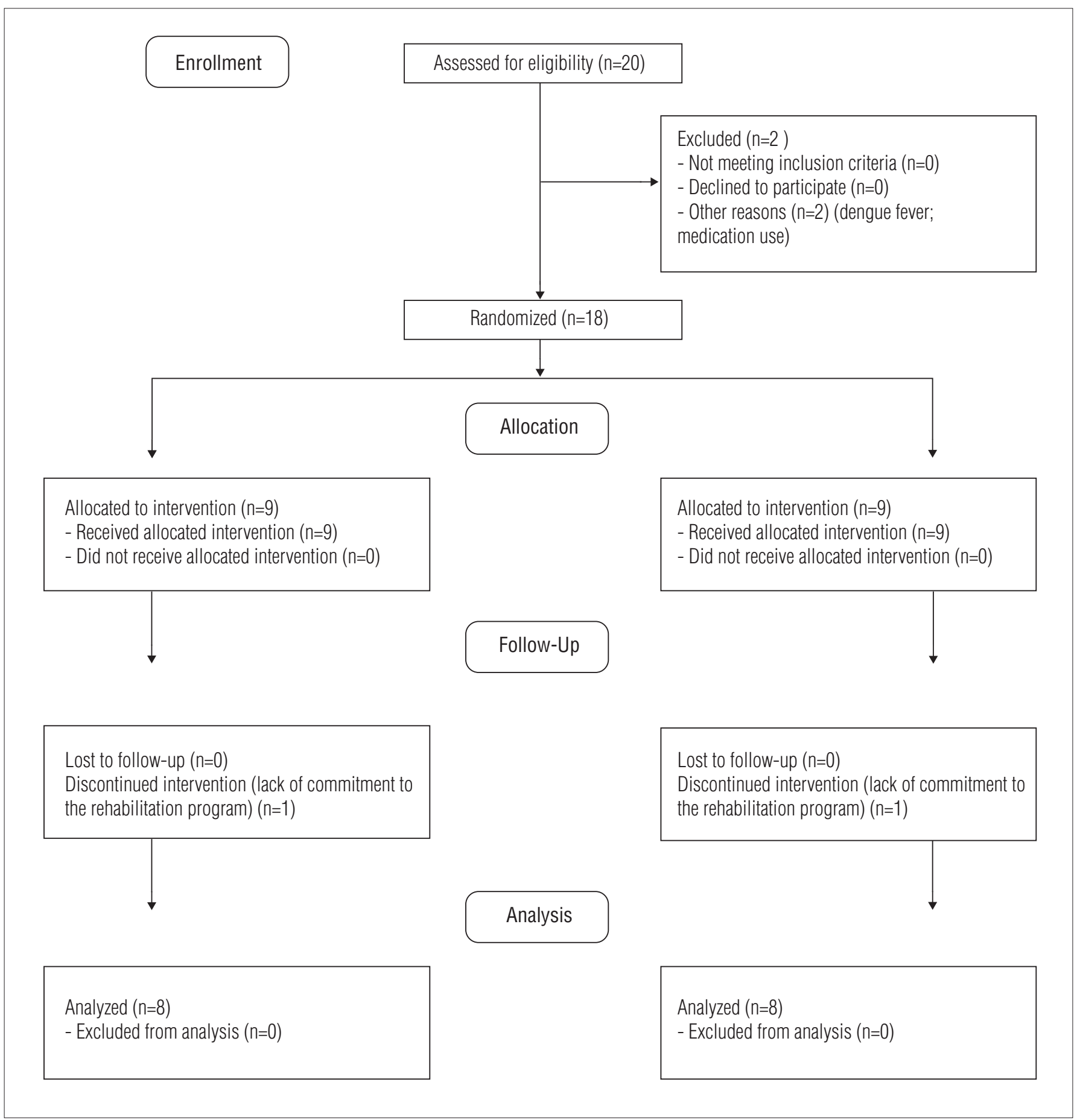

Figure 1. Flow diagram of subjects in Groups 1 and 2: enrollment, allocation, follow-up and analysis of subjects. 
were women (87.5\%) over 50 years of age (43.8\%), sedentary (62.5\%), and overweight (81.2\%), as illustrated in Table 1.

In relation to occupational aspects, the majority of the subjects were nurse's aids (68.8\%) with more than 15 years of hospital service (56.2\%), a work load of less than 30 hours a week (43.8\%), rotating work shift (62.5\%), more morning and afternoon work hours (43.8\%), and no other occupational responsibilities at other institutions (93.8\%).

It was seen that the right shoulder was more frequently involved with rotator cuff disorders (62.5\%) as it was more frequently used during occupational and daily activities. The majority of subjects reported pain for more than 6 months prior (37.5\%), made use of painkillers during the week prior to the initial interview (81.8\%), and were not discharged from their occupational responsibilities due to the pathology (56.2\%). Less than half of the subjects (31.2\%) claimed there was no relationship between shoulder pain and their occupational activities within the hospital. Most subjects in Groups 1 and 2 (87.5 and $87.5 \%$, respectively) followed the posture and joint protection guidance suggested by the physical therapist.

In relation to pain, a significant reduction $(\mathrm{p}<0.01)$ in intensity levels was observed in both groups after the physical therapy rehabilitation. However, no significant difference was

Table 1. Individual data, demographic data, professional aspects of nursing staff ( $n=16)$.

\begin{tabular}{lccc}
\hline \multicolumn{1}{c}{ Variables } & \multicolumn{2}{c}{$\mathrm{n}(\%)$} & Total \\
\cline { 2 - 3 } Sex & G1 & G2 & \\
\hline Female & $7(87.5)$ & $7(87.5)$ & $14(87.5)$ \\
\hline Male & $1(12.5)$ & $1(12.5)$ & $2(12.5)$ \\
\hline Age & & & \\
\hline $30 \leq 40$ years & $2(12.5)$ & $0(0.0)$ & $2(12.5)$ \\
\hline $41 \leq 50$ years & $2(25.0)$ & $5(6.5)$ & $7(43.8)$ \\
\hline$>50$ years & $4(50.0)$ & $3(37.5)$ & $7(43.8)$ \\
\hline Pysical exercise & & & \\
\hline Do not practice & $5(62.5)$ & $5(62.5)$ & $10(62.5)$ \\
\hline Walk & $1(12.5)$ & $3(37.5)$ & $4(25.0)$ \\
\hline Bicycle & $2(25.0)$ & $0(0.0)$ & $2(12.5)$ \\
\hline BMl & & & \\
\hline Normal weight & $2(25.0)$ & $1(12.5)$ & $3(18.8)$ \\
\hline Overweight & $3(37.5)$ & $3(37.5)$ & $6(37.5)$ \\
\hline Grade I obesity & $2(25.0)$ & $2(25.0)$ & $4(25.0)$ \\
\hline Grade Il obesity & $1(12.5)$ & $2(25.0)$ & $3(18.8)$ \\
\hline G1: Group 1; G2: Group 2: BMl: body mass index & &
\end{tabular}

G1: Group 1; G2: Group 2; BMI: body mass index. found between Groups 1 and 2 after the application of the Mann-Whitney test (non-parametric test for independent samples) (Table 2). Regarding quality of life (assessed by the WORC questionnaire), clinical improvement was observed after physical therapy intervention in Group 1 and significant statistical improvement in Group 2.

After the application of the Wilcoxon non-parametric test for paired samples for comparison of different domains before and after intervention in each group, a significant difference was observed only in the physical symptoms domain $(\mathrm{p}=0.03)$ for Group 1. However, Group 2 presented significant differences in all domains, including quality of life, as illustrated in Table 3.

In order to compare Groups 1 and 2, the Mann-Whitney test (non-parametric test for independent variables) was used. No significant differences were seen between groups in any of the domains, which prevents one from determining which treatment program was the most efficient (Table 3).

After the Wilcoxon test, no significant differences were observed between brute values of occupational satisfaction before and after intervention in each group. Furthermore, after the Mann-Whitney test, no additional significant differences were noted between groups (Table 4).

\section{Discussion $: \because$.}

This study evidenced that shoulder impingement syndrome are more frequent in women. Various studies in the literature report that the prevalence of musculoskeletal disorders is greater in women than men ${ }^{22-26}$. It is important to state that women compose the majority of the nursing staff and that this characteristic is due to historical factors ${ }^{27}$. The social division of work left women with activities related to taking care of the sick, children, and the elderly ${ }^{28-30}$. Furthermore, the greater incidence of musculoskeletal disorders in women's upper limbs can be due to physiological differences (such as hormonal conditions) or doing chores whilst caring for the family, which requires constant elevation of the $\operatorname{arms}^{22,25,29}$.

In relation to physical activity, the majority of subjects who participated in this study were sedentary and overweight. This prevalence of sedentary lifestyle, which is observed in

Table 2. Intensity of pain in nursing workers in Groups 1 and 2, before and after the application of physical therapy programs ( $n=16)$.

\begin{tabular}{lccccccc}
\hline & Mild & Before & Moderate & Severe & Mild & After & Moderate \\
& $(\leq 3)$ & $(4 \leq 7)$ & $(>7)$ & $(\leq 3)$ & Severe & $p$-value \\
& $1(12.5)$ & $3(37.5)$ & $4(50.0)$ & $5(62.5)$ & $3(37.5)$ & $0(0.0)$ & 0.01 \\
\hline Group 1 & $3(37.5)$ & $3(37.5)$ & $2(25.0)$ & $6(75.0)$ & $2(25.0)$ & $0(0.0)$ & 0.01 \\
\hline Group 2 & $4(25.0)$ & $6(37.5)$ & $6(37.5)$ & $11(68.75)$ & $5(31.25)$ & $0(0.0)$ & --- \\
\hline Total & & & & & & \\
\hline
\end{tabular}


the general population, represents a series of threats to the general health of the individual by stimulating the appearance of various chronic diseases, such as musculoskeletal disorders ${ }^{30,31}$. The literature illustrates that habitual physical exercises is beneficial for the general health and promotes, among other factors, improvement in muscle strength, flexibility, posture, stress management, muscle tension control, and provides adequate physical conditions for good quality of $\mathrm{life}^{32}$. Even though some studies have not established a relationship between musculoskeletal pain and the realization of physical activities ${ }^{33,34}$, other studies evidenced decreased pain levels in the shoulder and spine of individuals who exercised regularly practiced ${ }^{35,36}$. Regular exercise and the having only one professional occupation have been related to decreased incidence of musculoskeletal disorders and greater work capacity in nursing professionals ${ }^{36,37}$. Obesity has also been associated with musculoskeletal disorders of the upper limbs ${ }^{23}$, and a high body mass index has been associated with pain complaints in upper and lower extremity joints, as well as the lumbar spine ${ }^{27}$.

In the present study, significant pain reduction was evidenced, as assessed by the VNS, in both groups, although no significant differences were found between them. The success of conservative treatment of shoulder disorders can be measured by the intensity of the patient's reported pain ${ }^{29}$. Some authors relate the importance of establishing the patient's level of pain before and after clinical treatment ${ }^{29,30}$. The improvement of pain after physical therapy intervention can be the consequence of stretching and strengthening exercises for the rotator cuff muscles and scapula stabilizers, which were conducted by both groups. Another factor pertains to the use of cryotherapy, which is based on the reduction of pain intensity and frequency ${ }^{34,38}$, which was also applied to both groups. The results obtained in one study ${ }^{34}$ demonstrate that significant reduction in shoulder pain was also obtained after the use of cryotherapy. Decreased activation of the upper trapezius, associated with the increased activation of the lower trapezius and anterior serratus can also contribute to reduction in pain levels of the shoulder ${ }^{39}$.

Table 3. Difference in values between the domains of WORC questionnaire before and after the intervention, nursing workers in Groups 1 and 2 (Wilcoxon test) and the difference between Groups 1 and 2 (Mann-Whitney test) ( $n=16$ ).

\begin{tabular}{lrrc}
\hline Domains & Group 1 & Group 2 & Groups 1 and 2 \\
\hline Physical symptoms & 0.03 & 0.01 & 0.17 \\
\hline Sports/recreation & 0.05 & 0.01 & 0.20 \\
\hline Work & 0.23 & 0.01 & 0.52 \\
\hline Lifestyle & 0.09 & 0.01 & 0.14 \\
\hline Emotions & 0.48 & 0.01 & 0.37 \\
\hline Overall quality of life & 0.06 & 0.01 & 0.11 \\
\hline
\end{tabular}

WORC: Western Ontario Rotator Cuff Index.
Therefore, the objective of the strengthening program of this study was to promote scapular stabilization and increase strength of the rotator cuff muscles. In this manner, with the subsequent improvement in shoulder stabilization, it is possible to promote pain relief, which was a significant result obtained in this study in both groups.

A large portion of subjects from Groups 1 and 2 followed the posture and joint protection orientations. This can contribute to further decrease of pain and improvement in the patient's condition, and also illustrates the educational importance of physical therapists.

In both groups, there was significant improvement in quality of life, which is clinically important. However, this finding was statistically significant only for the group that carried out the proprioceptive exercises.

The proprioceptive exercises conducted in this study started at the beginning of the rehabilitation process in order to improve anticipatory muscle response and reestablish dynamic joint stability ${ }^{17,19}$. In this manner, the proprioceptive drills consisted of conscious stimuli in order to promote cognition and adaptations to sudden changes in joint positions, and therefore stimulate reflexive muscle activity ${ }^{17,19}$. These exercises may have improved muscle control during scapular and shoulder movement ${ }^{40}$ in Group 2. Proprioceptive exercises have been shown to be important in improving motor control in musculoskeletal disorders ${ }^{17,41}$. Deficits in rotator cuff and deltoid proprioception and motor control are key factors in the development of impingement syndrome because they influence shoulder movements ${ }^{42}$. This may be one of the main reasons why physical therapy is the best type of conservative treatment ${ }^{43}$. Physical therapists must incorporate the realization of proprioceptive exercises and functional activities in the treatment of rotator cuff disorders in order to reach successful motor outcomes ${ }^{44}$. Therefore, sensorimotor alterations are associated with rotator cuff disorders and can result in loss of shoulder function ${ }^{45}$.

The assessment of treatment results by means of quality of life instruments, such as the WORC, provides healthcare professionals with reliable and objective measures that aid in documenting the rehabilitation progress in order to compare them with pre-established data ${ }^{4,46}$. Therefore, quality of life and functional capacity can become a reference through which the

Table 4. Average values obtained from the questionnaire Occupational Stress Indicator (OSI) before and after the intervention, in Groups 1 and 2 ( $n=16)$.

\begin{tabular}{lccccc}
\hline Satisfaction & Groups & Average & $\begin{array}{c}\text { Standard } \\
\text { Deviation }\end{array}$ & Median & $\begin{array}{c}\text { Minimum- } \\
\text { Maximum }\end{array}$ \\
\hline \multirow{2}{*}{ Before } & G1 & 99.1 & 16.2 & 100.0 & $75-129$ \\
\cline { 2 - 6 } & G2 & 91.5 & 26.5 & 87.5 & $51-127$ \\
\hline \multirow{2}{*}{ After } & G1 & 87.0 & 18.2 & 89.0 & $62-107$ \\
\hline & G2 & 90.2 & 20.8 & 92.5 & $55-116$ \\
\hline
\end{tabular}


patients can evaluate the efficacy of their treatment $t^{44}$. Even though there is limited evidence in randomized and controlled studies in the literature that assessed the effect of physical therapy in the treatment of rotator cuff disorders ${ }^{40,47}$, the present research suggests that stretching, strengthening, and cryotherapy can significantly improve pain, and these procedures associated with proprioceptive exercises significantly contributed toward improving quality of life.

However, with regard to occupational satisfaction, no significant changes were seen after physical therapy intervention in nursing professionals with shoulder disorders in both groups. The instrument used in this study (Job Satisfaction Scale) was also applied in various other studies that assessed psychosocial aspects of work ${ }^{48-50}$. This instrument has displayed satisfactory reliability and validity values during quantitative assessment of psychosocial aspects of work ${ }^{51}$. However, no studies were found in the literature regarding the relationship between occupational satisfaction and bone and muscle disorders after an intervention program.

\section{Conclusions $: \because$.}

This study had limitations, such as a small sample size, even though the data collection period lasted for 13 months. In this manner, the results cannot be extrapolated and future research is needed to amplify knowledge regarding physical therapy rehabilitation on individuals with rotator cuff disorders, their quality of life and occupational satisfaction, in order to propose actions aimed toward health promotion in shoulder disorders.

The authors understand that it is fundamental to increase the number of studies regarding the occurrence of rotator cuff disorders and the various forms of physical therapy rehabilitation, in order to improve the occupational and daily activities of nursing professionals.

The results obtained in this study contribute toward an advance in scientific knowledge regarding treatment of rotator cuff disorders and provides methodological means by which future studies can be conducted.

\section{References $: \because$.}

1. Farias SMC, Teixeira OLC, Moreira W, Oliveira MAF, Pereira MO. Caracterização dos sintomas físicos de estresse na equipe de pronto atendimento. Rev Esc Enferm USP. 2011;45(3):722-9.

2. Stumm EMF, Scapin D, Fogliatto L, Kirchener RM, Hildebrant LM. Qualidade de vida, estresse e repercussões na assistência: equipe de enfermagem de uma unidade de terapia intensiva. Rev Textos \& Contextos. 2009;8(1):140-55.

3. Murofuse NT, Marziale MHP. Diseases of the osteomuscular system in nursing workers. Rev Latinoam Enferm. 2005;13(3):364-73.

4. Smith J, Dietrich CT, Kotajarvi BR, Kaufman KR. The effect of scapular protraction on isometric shoulder rotation strength in normal subjects. J Shoulder Elbow Surg. 2006;15(3):339-43.

5. Magnago TSBS, Lisboa MTL, Griep RH. Trabalho da enfermagem e distúrbio musculoesquelético: revisão das pesquisas sobre o tema. Esc Anna Nery Rev Enferm. 2008;12(3):560-5.

6. Smedley J, Inskip H, Trevelyan F, Buckle P, Cooper C, Coggon D. Risk factors for incident neck and shoulder pain in hospital nurses. Occup Environ Med. 2003;60(11):364-9.

7. Michener $L A$, Snyder AR. Evaluation of health-related quality of life in patients with shoulder pain: are we doing the best we can? Clin Sports Med. 2008;27(3):491-505.

8. Wessel RN, Lim TE, van Mameren H, de Bie RA. Validation of the western Ontario rotator cuff index in patients with arthroscopic rotator cuff repair: a study protocol. BMC Musculoskelet Disord. 2011;12: 64-73.

9. Lopes AD, Stadniky SP, Masiero D, Carrerca EF, Ciconelli RM, Griffin S. Tradução e adaptação cultural do WORC: um questionário de qualidade de vida para alterações do manguito rotador. Rev Bras Fisioter. 2006;10(3):309-15.

10. Cooper CL, Sloan SJ, Williams S. Occupational stress indicator management guide. London: NFER-Nelson; 1988

11. Robertson IT, Cooper CL, Williams J. The validity of the occupational stress indicator. Work Stress. 1990;4(1):29-39.

12. Pereira LV, Souza FAEF. Mensuração e avaliação da dor pós-operatória: uma breve revisão. Rev Latinoam Enferm. 1998;6(3):77-84.

13. Mello Junior WA, Arruda LRP, Coluccini AM, Nunes RPS, Pedro MAC, Souza MR, et al. Complications following medial opening wedge osteotomy of the knee: retrospective study. Rev Bras Ortop. 2011;46(1):64-8.

14. Kuhn JE. Exercise in the treatment of rotator cuff impingement: a systematic review and a synthesized evidence-based rehabilitation protocol. J Shoulder Elbow Surg. 2009;18(1):138-60.
15. Escamilla RF, Yamashiro K, Paulos L, Andrews JR. Shoulder muscle activity and function in common shoulder rehabilitation exercises. Sports Med. 2009;39(8):663-85.

16. Lech 0 . Fundamentos em cirurgia do ombro. Ortopedia e Reabilitação. $2^{\text {nd }}$ ed. Rio de Janeiro: Revinter; 2005.

17. Leporace G, Metsavaht L, Sposito MMM. Importância do treinamento da propriocepção e do controle motor na reabilitação após lesões músculo-esqueléticas. Acta Fisiátrica. 2009;16(3):126-31

18. Reinold MM, Escamilla R, Wilk EK. Current concepts in the scientific and clinical rationale behind exercises for glenohumeral and scapulothoracid musculature. J Orthop Sports Phys Ther. 2009;39(2):105-17.

19. Ludewig PM, Reynolds JF. The association of scapular kinematics and glenohumeral joint pathologies. J Orthop Sports Phys Ther. 2009;39(2):90-104.

20. Viveiros L, Polito MD, Simao R, Farinatti P. Respostas agudas imediatas e tardias da flexibilidade na extensão do ombro em relação ao número de séries e duração do alongamento. Rev Bras Med Esporte. 2004;10(6):459-63.

21. Tate AR, McClure PW, Young IA, Salvatori R, Michener LA. Comprehensive impairment-based exercise and manual therapy intervention for patients with subacromial impingement syndrome: a case series. J Orthop Sports Phys Ther. 2010;40(8):474-93.

22. Camargo PR, Haik MN, Filho RB, Mattiello-Rosa SM, Salvini TF. Pain in workers with shoulder impingement syndrome: an assessment using the DASH and McGILL pain questionnaires. Rev Bras Fisioter. 2007;11(2):161-7.

23. Roquelaure $\mathrm{Y}, \mathrm{Ha} \mathrm{C}$, Rouillon $\mathrm{C}$, Fouquet $\mathrm{N}$, Leclerc $\mathrm{A}$, Descatha $\mathrm{A}$, et al. Risk factors for upper-extremity musculoskeletal disorders in the working population. Arthritis Rheum. 2009;61(10):1425-34.

24. Choobineh A, Movahed M, Tabatabaie SH, Kumashiro M. Perceived demands and musculoskeletal disorders in operating room nurses of Shiraz city hospitals. Ind Health. 2010;48(1):74-84.

25. Leite $\mathrm{PC}$, Silva $\mathrm{A}$, Merighi MAB. A mulher trabalhadora de enfermagem e os distúrbios osteomusculares relacionados ao trabalho. Rev Esc Enferm USP. 2007;14(2):287-91.

26. Wijnhoven $\mathrm{HA}$, de Vet HC, Picavet HS. Sex differences in consequences of musculoskeletal pain Spine (Phila Pa 1976). 2007;32(12):1360-7.

27. Elias MA, Navarro VL. A relação entre o trabalho, a saúde e as condições de vida: negatividade e positividade no trabalho das profissionais de enfermagem de um hospital escola. Rev Latinoam Enferm. 2006;14(4):517-25. 
28. Costa FM, Vieira MA, Sena RR. Absenteísmo relacionado à doenças entre membros da equipe de enfermagem de um hospital escola. Rev Bras Enferm. 2009;62(1):38-44.

29. Garzedin DDS, Matos MAA, Daltro CH, Barros RM, Guimarães A. Pain severity in patients with painful shoulder syndrome. Acta Ortop Bras. 2008;16(3):165-7.

30. Antunes HKM, Santos RF, Cassilhas R, Santos RVT, Bueno OFA, Mello MT. Exercício físico e função cognitiva: uma revisão. Rev Bras Med Esporte. 2006;12(2):108-14

31. Matsudo SMM. Envelhecimento, atividade física e saúde. BIS, Bol Inst Saúde (Impr.). 2009;47:76-9.

32. Macedo CSG, Garavello JJ, Oku EC, Miyagusuku FH, Agnoll PD, Nocetti PM. Benefícios do exercício físico para a qualidade de vida. Rev Bras Ativ Fis Saúde. 2003;8(2):19-27.

33. Rechardt M, Shiri R, Karppinen J, Jula A, Heliövaara M, Viikari-Juntura E. Lifestyle and metabolic factors in relation to shoulder pain and rotator cuff tendinitis: a population-based study. BMC Musculoskelet Disord. 2010;11:165-76.

34. Osbahr DC, Cawley PW, Speer KP. The effect of continuous cryotherapy on glenohumeral joint and subacromial space temperatures in the postoperative shoulder. Arthroscopy. 2002;18(7): 748-754.

35. Nilsen TIL, Holtermann A, Mork PJ. Physical exercise, body mass index, and risk of chronic pain in the low back and neck/shoulders: Iongitudinal data from the Nord - Trøndelag Health Study. Am J Epidemiol. 2011;174(3):267-73

36. Raffone AM, Hennington EA. Avaliação da capacidade funcional dos trabalhadores de enfermagem. Rev Saúde Pública. 2005;39(4):669-76.

37. Magnago TSBS, Lisboa MTL, Griep RH, Kirchhof ALC, Camponogara S, Nonnenmacher CQ, et al. Condições de trabalho, características sociodemográficas e distúrbios musculoesqueléticos em trabalhadores de enfermagem. Acta Paul Enferm. 2010;23(2):187-93.

38. Calis HT, Berberoglu N, Calis M. Are ultrasound, laser and exercise superior to each other in the treatment of subacromial impingement syndrome? A randomized clinical trial. Eur J Phys Rehabil Med. 2011;47(3):375-80.

39. Andersen CH, Andersen LL, Mortensen OS, Zebis MK, Sjøgaard G. Protocol for shoulder function training reducing musculoskeletal pain in shoulder and neck: a randomized controlled trial. BMC Musculoskelet Disord. 2011;12:14-9.

40. Senbursa G, Baltaci G, Atay A. Comparison of conservative treatment with and without manual physical therapy for patients with shoulder impingement syndrome: a prospective, randomized clinical trial. Knee Surg Sports Traumatol Arthrosc. 2007;15(7):915-21.

41. Myers JB, Oyama S. Sensorimotor factors affecting outcome following shoulder injury. Clin Sports Med. 2008;27(3):481-90.

42. Wassinger CA, Myers JB, Gatti JM, Conley KM, Lephart SM. Proprioception and throwing accuracy in the dominant shoulder after cryotherapy. J Athl Train. 2007;42(1):84-9.

43. Metzker CAB. Tratamento conservador na síndrome do impacto do ombro. Fisioter Mov 2010;23(1):141-51

44. Tripp BL. Principles of restoring function and sensorimotor control in patients with shoulder dysfunction. Clin Sports Med. 2008;27(3):507-19.

45. Ludewig PM, Braman JP. Shoulder impingement: biomechanical considerations in rehabilitation. Man Ther. 2011;16(1):33-9.

46. Wright RW, Baumgarten KM. Shoulder outcomes measures. J Am Acad Orthop Surg. 2010;18(7):436-44

47. Kachingwe AF, Phillips B, Sletten E, Plunkett SW. Comparison of manual therapy techniques with therapeutic exercise in the treatment of shoulder impingement: a randomized controlled pilot clinical trial. J Man Manip Ther. 2008;16(4):238-47.

48. Chaves LD, Ramos LH, Figueiredo EN. Satisfação profissional de enfermeiros do Trabalho no Brasil. Acta Paul Enferm. 2011;24(4):507-13.

49. López-Araújo B, Segovia A0, Peiró JM. The job involvement modulating role in the relationship between stress and job satisfaction. Psicothema. 2007;19(1):81-7.

50. Marquese EC, Moreno CRC. Satisfação no trabalho e capacidade para o trabalho entre docentes universitários. Psicol Estud. 2009;14(1):75-82.

51. Martinez MC, Paraguay AIBB, Latorre MRDO. Relação entre satisfação com aspectos psicossociais e saúde do trabalhador. Rev Saúde Pública. 2004;38(1):55-61. 